Vol. 2 No. 2, Desember 2018, 133-140

P-ISSN: 2549-208X

\title{
IMPLEMENTASI METODE LANGSUNG DALAM PEMBELAJARAN BAHASA ARAB
}

\author{
Zulli Umri Siregar, Arif Rahman Nurhakim \\ UIN Sunan Gunung Djati Bandung \\ Coresponding Email: zulli.siregar@uinsgd.ac.id
}

\begin{abstract}
ملخص البحث
ينطلق هذا البحث من أن طرق تدريس اللغة العربية المستخدمة له تزل تجري على الطريقة القديمة. يبدو ذلك من تعليم اللغة العربية الشائع في كثير من المدارس والمعاهد، حيث كانت طريقة القواعد والترجمة تعد أفضل الطرق لتدريس اللغة العربية. في هذا البحث القصير، يريد الباحث ان يقدم الطريقة المبشرة لتعليم اللغة العربية حيث كان التعليم مبنيا على عرض الاقتران المباشر حتى لا يحتاج التلاميذ إلى الترجماة. وأغراض هذا البحث هي معرفة ملائمة استخدام للطريقة المباشـرة. والطريقة المستخدمة هي طريقة التحليل النظري. ونتيجة البحث تدل على أن هذه الطريقةملائمة للتلاميذ الذين يريدون مهارة الكلام. الكلمات الرئيسية: التطبيق، الطريقة المباشرة، اللغة العربية.
\end{abstract}

\begin{abstract}
Abstrak
Penelitian ini bertolak dari banyaknya penggunaan metode-metode dalam pembelajaran bahasa Arab di Indonesia dari dulu sampai sekarang. Hal itu nampak dari berbagai metode yang digunakan dalam pengajaran Bahasa arab di sekolah dan pesantren, bahkan perguruan tinggi. Metode kaidah terjemah paling banyak digunakan dalam pengajaran bahasa Arab. Pada penelitian ini peneliti akan memaparkan metode mubÂSyirAh dalam pembelajaran bahasa Arab yang lebih didasarkan pada belajar bahasa Arab sama dengan belajar bahasa ibu, yakni penggunaan bahasa secara langsung dan intensif dalam komunikasi. Penelitian ini bertujuan untuk mengetahui hal-hal yang berkaitan dengan metode langsung (tharîaAh mubÂSyirah) dalam pembelajaran bahasa Arab dan langkahlangkah teknis yang dilakukan dalam proses belajar mengajar bahasa Arab. Metode yang digunakan dalam penelitian ini adalah metode analisis teori. Adapun hasil penelitiannya bahwa pendekatan yang digunakan pada metode ini adalah pendekatan komunikatif, sedangkan metode dan teknik pembelajarannya lebih mengutamakan kemampuan berbicara, bukan kemampuan menulis dan guru memperkenalkan suatu kata atau frasa baru dengan mendemontransikan maknanya melalui pemakaian realia, gambar-gambar, atau pantomim.
\end{abstract}

Kata Kunci: Bahasa Arab, Metode Langsung, Implementasi. 
Ta'lim al-'Arabiyyah : Jurnal Pendidikan Bahasa Arab dan Kebahasaaraban, 2 (2), 2018

\section{PENDAHULUAN}

Bahasa Arab di luar kawasan Arab termasuk di Indonesia pertama-tama dikesani sebagai bahasa agama Islam. Karena Al-Qur'an dan Al-Sunnah sebagai dua sumber utama ajaran Islam berbahasa Arab. Demikian pula buku-buku penjelasan dari dua sumber tersebut dan khasanah ilmu pengetahuan dan seni sastra warisan zaman keemasan Islam banyak ditulis dalam bahasa Arab. Lebih dari itu, bahasa Arab merupakan bahasa internasional yang diakui secara resmi oleh PBB selain bahasa Inggris, Mandarin, Spanyol, Rusia dan Prancis. Bahasa Arab dewasa ini telah menjadi bahasa pergaulan Internasional yang penggunaannya cukup luas. Mengingat urgensi tersebut, maka penguasaan bahasa Arab oleh generasi muslim khususnya menjadi sangat penting, selain untuk memahami sumber-sumber agama Islam, juga untuk komunikasi internasional terutama dengan saudara-saudara seagama di negera-negara Arab. Lembaga-lembaga pendidikan Islam dituntut mempersiapkan generasi muslim yang menguasai bahasa Arab.

Di Indonesia berbagai upaya untuk memenuhi tuntutan tersebut telah dan sedang dijalankan, baik oleh lembaga pendidikan tradisional maupun modern. Beragam pendekatan, metode dan teknik dicoba terapkan untuk mencapai tujuan pembelajaran bahasa Arab. Satu hal yang penting untuk dijadikan alasan penggunaan suatu metode tertentu dalam pembelajaran bahasa Arab ialah tujuan pembelajaran. Setiap metode seperti metode kaidah dan tarjamah, metode langsung, metode audiolingual, metode membaca dan metode gabungan adalah baik jika sesuai dengan tujuan pembelajaran. Apabila pembelajaran bahasa Arab bertujuan agar peserta didik mampu berkomunikasi sebagaimana para penutur asli maka metode yang cocok untuk tujuan ini ialah metode mubâsyirah atau metode langsung. Makalah ini akan membahas masalah-masalah yang berkaitan dengan metode langsung (tharíqahmubâsyirah) dalam pembelajaran bahasa Arab, serta bagaimana langkah-langkah teknis yang dijalankan dalam proses belajar mengajar bahasa Arab dengan menggunakan metode mubâsyirah.

\section{Kemunculan Metode Langsung}

Metode langsung (al-tharîah al-mubâsyirah/direct method) disebut juga metode Berlitz (Izzan, 2011: 88) dikembangkan oleh Charles Berlitz, seorang ahli dalam pengajaran bahasa, di Jerman menjelang abad ke-19 (Hermawan, 2011: 175). Metode langsung muncul bersamaan dengan kemunculan metode Gouin and the Series Methode yang dikembangkan pada akhir tahun 1800-an oleh Francois Gouin orang Perancis yang mengajar bahasa Latin. Kedua metode ini memiliki kemiripan dalam hal menghindari penjelasan gramatikal dan menghindari terjemahan dalam pengajaran bahasa. Kedua metode ini muncul sebagai reaksi penolakan terhadap metode tua yang telah berkembang sejak berabad-abad sebelumnya yaitu metode klasik atau Grammar Translation Method yang menitikberatkan penguasaan kaidah gramatikal dan kemampuan menerjemahkan. Dalam perkembangannya metode langsung menjadi lebih dikenal secara meluas daripada Gouin and the Series Methode (Lengkawati dalam Revitalisasi Pendidikan Bahasa, 2003: 72). 
Ta'Cim al-'Arabiyyah : Jurnal Pendidikan Bahasa Arab dan Kebahasaaraban, 2 (2), 2018

\section{Konsep Dasar Metode Langsung dalam Pembelajaran Bahasa Arab}

Metode langsung berasumsi bahwa belajar bahasa Arab sama dengan belajar bahasa ibu, yakni penggunaan bahasa secara langsung dan intensif dalam komunikasi. Para pelajar menurut metode ini, belajar bahasa Arab dengan cara menyimak dan berbicara, sedangkan membaca dan mengarang dapat dikembangkan kemudian, sebab inti bahasa adalah menyimak dan berbicara. Oleh karena itu mereka harus dibiasakan berpikir dengan bahasa Arab. Maka untuk mencapai ini semua penggunaan bahasa ibu dan bahasa kedua ditiadakan sama sekali. Bahkan unsur tata bahasa di dalam metode ini tidak terlalu diperhatikan, sebab tekanan intinya adalah bagaimana agar pelajar pandai menggunakan bahasa Arab yang dipelajari, bukan pandai tentang bahasa Arab yang dipelajari. Tata bahasa Nahwu Sharaf hanya diberikan melalui situasi kontekstual dan dilakukan secara lisan, bukan dengan cara menghafalkan kaidah-kaidah (Hermawan, 2011: 177).

Metode langsung dalam pembelajaran bahasa Arab memiliki tujuan agar para pelajar mampu berkomunikasi dengan bahasa Arab yang dipelajarinya seperti pemilik bahasa ini. Untuk mencapai kemampuan ini para pelajar diberi banyak latihan secara intensif. Latihan-latihan ini diberikan dengan asosiasi langsung antara kata-kata atau kalimat-kalimat dengan maknanya, melalui demonttrasi/peragaan, gerakan, mimik muka dan sebagainya.

Menurut Abdurahman (2010: 21) ada beberapa hal yang perlu diperhatikan dalam penggunaan metode langsung dalam pembelajaran bahasa Arab, antara lain:

1. Materi yang diajarkan terdiri dari kata-kata dan struktur kalimat yang banyak digunakan sehari-hari.

2. Gramatika Nahwu Sharaf diajarkan melalui situasi dengan cara lisan, bukan dengan cara menghafal.

3. Arti yang konkret diajarkan dengan menggunakan benda-benda, sedangkan arti yang abstrak diajarkan melalui asosiasi.

4. Latihan mendengar dan meniru percakapan dalam bahasa Arab banyak diberikan agar dapat dicapai penguasaan bahasa Arab secara otomatis.

5. Melatih cara berpikir menurut bahasa Arab yang diajarkan.

6. Berani mempraktekkan percakapan, dengan menghilangkan rasa malu dan takut salah.

7. Memperbanyak perbedaharaan kata-kata dan kalimat secara kontinu (Tayar Yusuf, 1985:9), sebagai contoh: jika setiap hari kita menghafal lima kosakata, maka dalam satu bulan kita telah dapat menguasai kosa kata bahasa arab sebanyak 150 kata, dan untuk satu tahun kita telah menguasai 1900 kata, dan begitulah seterusnya.

8. Selalu melatih alat pendengaran dan pengucapan agar menjadi fasih dan lancar.

9. Terus menerus banyak membaca buku-buku dalam bahasa Arab. 
Ta'lim al-'Arabiyyah : Jurnal Pendidikan Bahasa Arab dan Kebahasaaraban, 2 (2), 2018

\section{Ciri-ciri Penerapan Metode Langsung dalam Pembelajaran Bahasa Arab}

Dari konsep metode langsung di atas, dapat dikemukakan bahwa karakteristik metode langsung dalam pembelajaran bahasa Arab adalah:

1. Berbahasa adalah berbicara, maka berbicara dalam bahasa Arab merupakan aspek yang harus diperioritaskan. Jika ada materi dalam bentuk bacaan, maka bacaan itu pertama kali disajikan secara lisan.

2. Sejak dini pelajar dibiasakan berpikir dalam bahasa Arab yang dipelajari. Cara ini dilakukan agar pelajar pandai menggunakan bahasa Arab secara otomatis layaknya bahasa ibu.

3. Bahasa ibu dan bahasa kedua atau terjemahan ke dalam dua bahasa tersebut tidak digunakan.

4. Tidak begitu memperhatikan tata bahasa Nahwu Sharaf, kalaupun ada hanya diberikan dengan mengulang-ulang contoh kalimat secara lisan, bukan dengan menjelaskan definisi atau menghapalkannya.

5. Ada asosiasi langsung antara kata-kata atau kalimat-kalimat dengan maknanya, melalui demonttrasi/peragaan, gerakan, mimik muka, gambar bahkan alam nyata. Atas dasar ini proses belajar dapat dilakukan baik di dalam kelas maupun di luar kelas.

6. Untuk memantapkan pelajar dalam menguasai bahasa Arab yang dipelajari, pengajar memberikan latihan berulang-ulang dengan contoh dan hapalan (Hermawan, 2011: 178).

Ahmad Izzan (2011: 87) menggarisbawahi ciri-ciri metode langsung dalam pembelajaran bahasa Arab sebagai berikut.

1. Materi pelajaran pertama-tama diberikan kata-demi kata, kemudian struktur kalimat.

2. Kaidah nahwu sharaf diajarkan hanya bersifat sambil lalu, dan pelajar tidak dituntut menghapal kaidah-kaidah, yang utama adalah pelajar mampu berbicara dalam bahasa Arab dengan baik.

3. Dalam proses pengajaran senantiasa menggunakan alat praga, baik alat praga langsung (benda tiruan) maupun melalui gambar-gambar atau gerakan-gerakan tertentu.

4. Setelah masuk kelas, pelajar benar-benar dikondisikan untuk menerima pelajaran dan bercakap-cakap dalam bahasa arab yang dipelajari, dan dilarang menggunakan bahasa lain. 
Mengacu pada informasi dari para ahli tentang metode langsung, terdapat beberapa intisari ciri khas dari metode ini. Intisari ciri-ciri tersebut bila dikelompokkan berkenaan dengan lima hal, yaitu:

\section{Tujuan Pembelajaran}

Tujuan belajar bahasa Arab dengan metode langsung mengarah pada kemampuan bicara dalam bahasa Arab dengan baik dan benar sehingga mampu berkomunikasi dengan penutur Arab asli.

\section{Aktivitas Berbahasa dalam Proses Belajar dan Mengajar (PBM)}

Metode langsung dalam pembelajaran bahasa Arab dicirikan dengan aktivitas berbahasa lisan yang menonjol, yaitu:

a. penggunaan bahasa Arab secara langsung sebagai pengantar dalam proses belajar dan mengajar. Pengajar sedapat mungkin bahkan sama sekali tidak menggunakan bahasa ibu atau bahasa kedua.

b. latihan intensif pada keterampilan menyimak dan berbicara sekaligus memupuk kebiasaan cara berpikir dalam bahasa Arab. Untuk itu pertamatama guru mengkondisikan peserta didik untuk menerima pelajaran dalam bahasa Arab dan memberi arahan agar mereka tidak menggunakan bahasa lain dalam bertanya jawab. Contoh-contoh dialog disajikan untuk disimak dengan baik dan ditiru sampai lancar kemudian dipraktekan antar peserta didik secara bergantian. Beberapa peserta yang sudah maju diberi kesempatan mengadakan dialog yang dianalogikan atau dikembangkan dari contoh yang disajikan.

\section{Kontent, Penyajian dan Pembahasan Materi Ajar}

a. Konten materi disajikan secara bertahap (tadarru) disesuaikan dengan taraf kemampuan peserta didik.

b. Materi ajar disajikan pertama kali secara lisan, peserta didik diarahkan untuk menyimak saja tanpa melihat bacaan tertulis.

c. Untuk memberi pemahaman tentang bentuk kata dan struktur kalimat, pengajar tidak membahas/menganalisis kaidah nahwu-sharafnya dan tidak memberi hafalan kaidah, melainkan cukup dengan contoh-contoh yang relevan secara lisan.

d. Untuk memberi pemahaman makna kata atau kalimat, pengajar tidak menerjemahkannya ke bahasa lain, tetapi membahasnya dalam bahasa Arab melalui asosiasi, padanan kata, peragaan, gerakan tertentu, mimic muka dan alat peraga seperti benda sebenarnya, benda tiruan dan gambar.

\section{Aktivitas Peserta Didik}

Metode langsung dalam pembelajaran bahasa Arab dicirikan dengan partisipasi aktif peserta didik dalam kegiatan yang mendukung kemampuan berbahasa Arab lisan, yaitu:

a. melatih pendengaran dan pengucapan agar terbiasa dengan tuturan bahasa Arab. 

b. Banyak mempraktekan percakapan bahasa Arab tanpa dibebani rasa malu dan takut salah.
c. Memperbanyak perbendaharaan kosa kata dan kalimat bahasa Arab
d. Banyak membaca buku-buku berbahasa Arab.

\section{Evaluasi Hasil Belajar}

Evaluasi hasil belajar bahasa Arab dengan menggunakan metode langsung diberikan secara liasn dengan penekanan pada keterampilan menyimak dan berbicara.

\section{Implementasi Metode Langsung dalam Pembejalaran Bahasa Arab}

Langkah-langkah pembelajaran bahasa Arab dengan menggunakan metode langsung, yaitu:

1. memilih topik yang sesuai dengan taraf kemampuan peserta didik;

2. kemudian guru mengucapkan kata-kata atau kalimat yang sesuai dengan tingkat kemampuan anak didik dengan menggunkan alat peraga bila diperlukan (Ibrasyi, 1955:264).

Hal ini sesuai dengan Yusuf (1997:193) yang mengatakan bahwa dalam pembelajaran bahasa Arab perlu dipersiapkan materi dengan baik dan ditetapkan topic pembahasan. Materi disesuaikan dengan taraf perkembangan dan kemampuan anak didik, dan dimulai dengan kata-kata yang dapat dimengerti anak didik. (Yusuf, 1997:193). Lebih lanjut Ahmad Fauzi (1998:14) mengatakan bahwa dalam mengajarkan bahasa Arab dengan menggunakan metode langsung arti konkret perlu dijelaskan dengan menggunakan alat peraga, sedangkan arti yang abstrak dijelaskan melalui asosiasi. Dan sejak permulaan peserta didik dilatih cara berfikir menurut bahasa yang diajarkan. Demikian juga latihan mendengar dan meniru banyak diberikan agar dapat dicapai penguasaan bahasa secara otomatis.

Acep Hermawan (2011: 181) mengurai secara umum langkah-langkah penerapan metode langsung dalam pembelajaran bahasa Arab sebagai berikut:

1. Pendahuluan, memuat berbagai hal yang berkaitan dengan materi yang akan disajikan baik berupa apersepsi, atau tes awal tentang materi atau yang lainnya.

2. Guru memberikan materi berupa dialog-dialog pendek yang rilek, dengan bahasa Arab yang biasa digunakan sehari-hari secara berulang-ulang. Materi ini mula-mula disajikan secara lisan dengan bantuan gerakan-gerakan, isyaratisyarat, dramatisasi-dramatisasi, atau gambar-gambar. Bahkan jika perlu pelajar dibawa ke alam nyata untuk memudahkan peragaan atau menunjukan bendabenda yang berkaitan dengan materi yang disajikan. Jika sudah mantap bisa dikembangkan ke dalam tulisan.

3. Pelajar diarahkan untuk disiplin menyimak dialog-dialog tersebut, lalu menirukan dialog-dialog yang disajikan sampai lancar. 
Ta'lim al-'Arabiyyah : Jurnal Pendidikan Bahasa Arab dan Kebahasaaraban, 2 (2), 2018

4. Para pelajar dibimbing menerapkan dialog-dialog itu dengan teman-temannya secara bergiliran. Pelajar yang sudah maju diberi kesempatan untuk mengadakan dialog lain yang dianalogikan dengan contoh yang diberikan guru.

5. Struktur/tata bahasa diberikan bukan dengan menganalisa nahwu, melainkan dengan memberikan contoh-contoh secara lisan yang sedapat mungkin menaik perhatian pelajar untuk mengambil kesimpulan-kesimpulan sendiri.

6. Sebelum penutup, jika diperlukan, evaluasi akhir berupa pertanyaan-pertanyaan dialog yang harus dijawab oleh pelajar sebagaimana pola-pola dialog di atas. Pelaksanaannya bisa saja secara individual atau kelompok, sesuai dengan situasi dan kondisi. Jika tidak memungkinkan karena waktu, misalnya, guru dapat menyajikannya berupa tugas yang harus dikerjakan di rumah masing-masing pelajar.

\section{SIMPULAN}

Dari uraian di atas dapat disimpulkan bahwa metode langsung cocok digunakan untuk pembelajaran bahasa Arab yang bertujuan agar peserta didik mampu berkomunikasi dengan bahasa Arab seperti penutur asli atau mendekatinya. Jadi kemahiran bahasa yang ditekankan pada metode langsung ialah keterampilan menyimak dan berbicara, sehingga yang diperbanyak dalam proses pembelajaran ialah latihan menyimak dialog dan mempraktekannya. Dengan begitu penguasaan terhadap unsur-unsur bahasa seperti pelapalan bunyi, pembentukan kata dan penyusunan kalimat sudah inklud dalam latihan dialog. Kefasihan contoh dialog yang disajikan dan ketepatan siswa menirukannya sangat dituntut dalam metode ini, sehingga metode ini akan mencapai hasil maksimal jika diterapkan oleh guru yang fashîh dan balîgh.

\section{DAFTAR PUSTAKA}

Abdurahman, Maman, Pengembangan Materi Ajar Bahasa Arab Terpadu untuk Meningkatkeanpenguasaan Kemahiran Berbahasa Arab Mahasiswa Perguruan Tinggi Umum, Ringkasan Penelitian, Universitas Pendidikan Indonesia (UPI), Bandung, 2010 .

Brown, H. D. 1977. Some limitations of C-L/CLL models of second language teaching. TESOL QuArterly 11(4): 365-372. Community LAngu Age Le Arning. TESOL QuArterly 11(4): 373-382.

Curran, C. A. 1972. Counseling-LeArning: A Whole-Person Model for EducAtion. New York: Grune and Stratton.

Curran, C. A. 1976. Counseling-LeArning in Second LAnguAges. Apple River, 111: Apple River Press.

Hermawan, Acep, Metodologi Pembeljaran Bahasa Arab, Remaja Rosda Karya, Bandung, 2011.

Izzan, H. Ahmad, Metodologi Pembelajaran Bahasa Arab, Humaniora, Bandung, 2011. 
Ta'lim al-'Arabiyyah : Jurnal Pendidikan Bahasa Arab dan Kebahasaaraban, 2 (2), 2018

La Forge, P. G. 1975b. ReseArch Profiles with Community LAnguAge LeArning. Apple River, 111.: Apple River Press.

La Forge, P. G. 1983. Counseling And Culture in Second LAnguage Acquisition. Oxford: Pergamon.

La Forge, P. G. 1971. Community LAnguAge LeArning: A pilot study. LAnguAge LeArning 21(1): 45-61.

La Forge. P. G. 1975a. Community LAnguAge LeArning: The Japanese case. In F. C. C. Peng (ed.), LAnguage in JApAnese Society. Tokyo: University of Tokvo Press. 215-246.

Lengkawati dalam A. Chaedar Alwasilah dan Hobir Abdullah (editor), Revitalisasi Pendidikan Babasa, CV Andira, Bandung, 2003.

Lim, K. B. 1968. The unified lAngu Age project. RELC Journ Al 9(1): 19-27.

Mackey, W. F. 1972. BilinguAl EducAtion in A BinAtionAl School. Rowley, Nkss.: Newbury House. Moskowitz, G. 1978. CAring And ShAding in the Foreign LAnguAge Class. Rowley, Mass.: Newbury House.

Munby, J. 1978. Communicative Syllabus Design. Cambridge: Cambridge University Press.

Rardin, J. 1976. A Counseling-Learning model for second language learning.

Rardin, J. 1977. The language teacher as facilitator. TESOL QuArterly 11(4): 383-38. Rogers, C. R. 1951. Client-Centered TherApy. Boston: Houghton Mifflin. TESOL Newsletter 10(2): 21-22. 